\title{
The Effect of Abuse-Deterrent Extended-Release Oxycodone Leads to Inappropriate Conclusions with Over Estimation of Safety of Abuse-Deterrent Formulations
}

\section{To The Editor:}

Larochelle et al (1) published an original investigation on rates of opioid dispensing and overdose after the introduction of abuse-deterrent, extended-release oxycodone and the withdrawal of propoxyphene in the JAMA Internal Medicine. We believe that Larochelle et al may have misinterpreted the causes of opioid overdoses and the consequences of abuse-deterrent opioid formulations. These assumptions could lead readers to increase opioid prescriptions since abuse-deterrent, extended-release oxycodone is believed to be safe. In fact, overuse, abuse, and misuse of opioids have been a major issue of consideration for years, not only among some physicians, but also among regulators (2-5).

Opioid prescriptions for chronic noncancer pain skyrocketed in the late 1990s. Initially, this was the result of the lifting of opioid prescribing restrictions by state medical boards. A multitude of other factors then contributed to runaway opioid prescriptions. They include the implementation of pain management standards describing pain as the fifth vital sign by the Joint Commission on Accreditation of Health Care Organizations (4); the concept of a patient's right to pain relief, resulting in validation of provider sensibilities towards increase opioid prescribing, and patients seeking more frequent, stronger opioids. Simultaneously, there were multiple organizations calling for opioid treatment for patients with chronic noncancer pain. Of concern, some of these organizations enjoyed material financial support from the pharmaceutical industry. (5).

Overall, an atmosphere has been created, though largely well intended, that justified increased opioid prescriptions based on a belief that opioid prescribing is necessary, safe, and effective as long as these medications are prescribed by a physician. We are writing this letter to the editor because it would appear that Larochelle et al seem to echo these misconceptions. To our knowledge there is no significant evidence that either short- or long- opioids, alone or in combination improve functional status when prescribed chronically for pain.

Various efforts to decrease opioid use include regulations, prescription monitoring programs, educating providers and patients, and abuse-deterrent formulations. Abuse-deterrent formulations alone, with limited distribution, will not prevent people receiving high-doses of opioids from overdosing. In fact, they may even increase them with patients believing they are safe with the same effect. Additionally, the disadvantage is that once patients are started on long-acting opioids, they will also be receiving short-acting opioids for breakthrough pain, thus increasing the overall use and dosages of opioids.

\author{
Laxmaiah Manchikanti, MD \\ Clinical Professor \\ Anesthesiology and Perioperative Medicine \\ University of Louisville \\ Louisville, Kentucky \\ Medical Director \\ Pain Management Center of Paducah \\ 2831 Lone Oak Road \\ Paducah, KY 42003 \\ E-mail: drlm@thepainmd.com
}

\author{
Sairam Atluri, MD \\ Medical Director \\ Tri-State Spine Care Institute \\ Cincinnati, Ohio \\ E-mail: saiatluri@gmail.com
}

Joshua A. Hirsch, MD

Vice Chair, Interventional Care

Service Line Chief

Interventional Radiology

Director

Endovascular and Interventional Neuroradiology

Chief, Neurolnterventional Spine Service

Co-Director, Neuroendovascular Program

Department of Radiology

Massachusetts General Hospital

Harvard Medical School.

E-mail: hirsch@snisonline.org 


\section{References}

1. Larochelle MR, Zhang F, Ross-Degnan D, Wharam JF. Rates of opioid dispensing and overdose after introduction of abuse-deterrent extended-release oxycodone and withdrawal of propoxyphene. JAMA Intern Med 2015 Apr 20. [Epub ahead of print]

2. Kolodny A, Courtwright DT, Hwang CS, Kreiner P, Eadie JL, Clark TW, Alexander $\mathrm{GA}$. The prescription opioid and hero- in crisis: A public health approach to an epidemic of addiction. Annu Rev Public Health 2015, 36: 559-574.

3. Mehendal AW, Goldman MP, Mehendale RP. Opioid overuse pain syndrome (OOPS): The story of opioids, Prometheus unbound. J Opioid Manag 2013; 9:421-438.

4. Atluri S, Sudarshan G, Manchikanti L.
Assessment of the trends in medical use and misuse of opioid analgesics from 2004 to 2011. Pain Physician 2014; 17:E119-E128.

5. Manchikanti L, Atluri S, Hansen $\mathrm{H}, \mathrm{Be}-$ nyamin RM, Falco FJ, Helm li S, Kaye $A D$, Hirsch JA. Opioids in chronic noncancer pain: Have we reached a boiling point yet? Pain Physician 2014; 17:E1-E10. 